\title{
Modeling Cultural Competence in Teaching Humanities to Medical Students
}

\author{
Oksana Isayeva* \\ Candidate of philological sciences, Associate Professor of the Department of Foreign Languages, Danylo Halytskyi Lviv National \\ Medical University, Lviv, Ukraine \\ *Corresponding author: vanivska@inbox.ru
}

Received September 25, 2014; Revised October 27, 2014; Accepted December 14, 2014

\begin{abstract}
The article highlights the issue of humanization of higher medical education, based primarily on expanding the informational content of culture competence in training humanities. Humanitarian education as a part of culture should form the capacity for introspection, self-awareness, self-reflection to personal actions and to surrounding events. Culture competence plays especially essential role in further practice of medical specialists. The background of cultural competency at higher medical universities can be understood as those acquired skills which help medical students recognize cultural differences and facilitate communication between patients, their relatives and colleagues who have various ways of understanding health, sickness and body functioning. Culture competence includes cultural knowledge, sensitivity, awareness, clinical skills and abilities which constitute rules, norms and strategies. The teachers of humanitarian disciplines should elaborate and implement into educational process confirmed strategies for empowering medical students to become active, responsible life-long learners and selfmotivated, interdependent, self-aware, self-managing, self-confident, emotionally intelligent and culturally competent specialists. Learning humanitarian subjects at higher medical educational establishments can offer an exceptional opportunity to help medical students develop learning skills, especially relating to cultural competence.
\end{abstract}

Keywords: culture competence, culture, medical students, higher medical education, humanitarian disciplines

Cite This Article: Oksana Isayeva, "Modeling Cultural Competence in Teaching Humanities to Medical Students.” American Journal of Educational Research, vol. 2, no. 12B (2014): 51-55. doi: 10.12691/education-212B-10.

\section{Introduction}

Currently, modern Ukrainian higher medical education as a complex developing system cannot be left to the canons of old ideas, norms, values, rules of culture and human activity. Thus, advancement of higher education presupposes the implementation of completely new scientific methodologies and pedagogical theories in training future specialists of higher medical education. Nevertheless, the necessary step for successful reform of higher medical education is to develop culture competence of higher medical educational institutions in general and the organizational culture of their staff, leaders and students in particular. Culture is known to be an important part of modern Ukrainian society from the view of technocratic development, high-tech technologies and even current situation. Accordingly, supporting the statement "if culture is considered to be a specific way of mastering reality, knowledge, technologies (skills) and the meaningfulness or priorities (values) should be constituent structural elements of culture” [4].

That is why humanization of higher medical education, based primarily on expanding the informational content of culture competence to teaching humanities, ensures mastering of humanistic values, forming of humanistic outlook, and creating harmoniously developed personality. It is suggested that the concept of "culture" cannot be separated from the concept of "activity", as both these categories are historically interdependent and closely interconnected in the teaching process of medical students. It is believed that the concept of "culture" is based on the eternal values of goodness, truth and beauty. Thus, developing the concept of "culture", Western specialists distinguish the following levels of organizational culture as artifacts and objects of human activity, values and basic installation of human being. It is necessary to note that humanitarian education as a part of culture competence creation should form the capacity for assertiveness, introspection, self-awareness, self-reflection to personal actions and to surrounding events: spiritual, historical, political, economic, environmental, social and natural.

Therefore, the development of culture competence in future doctors as a planned process, based on a certain algorithm of foreign language study and humanities in particular becomes principally significant at higher educational establishments. Today, contemporary social progress in Ukraine depends on both the intellectual and cultural level of human development, personal knowledge and moral position of young people. Consequently, it is essential to trace the content and direction, tactics, strategy and immediate prospects of higher medical humanitarian 
education, which constitute culture, nature and ideology of future generations, particularly medical caregivers.

\section{Research Methodology}

Recently, Ukrainian higher medical schools have begun to recognize a need in cultural competency training in the process of teaching humanities. Therefore, teaching process requires the enhancement of existing skills rather than developing new abilities. The teachers of humanitarian disciplines may encounter some barriers, including situational, philosophical, pedagogical, social, and cultural issues caused by the lack of personal culture or complex difficulties in the learning environment. Thus, the background of cultural competency at higher medical universities can be understood as those acquired skills which help medical students understand cultural differences and facilitate communication between patients, their relatives and colleagues who have various ways of understanding health, sickness and body functioning.

It should be noted that culture competence plays especially essential role in further future practice of medical specialists as velocity and accuracy of decision making in the choice of treatment or diagnosis tactics as it may cost life, emergency and even urgent operations for the patient. In other words, culture is considered to be the system of shared values that define the style of activity, communication and behavior of doctors and distinguish them among patients, relatives and their colleagues. As scientist P. Sorokin correctly pointed out that without individual's assessments "all the phenomena of human interaction become simply biophysical phenomena and deprived of their significant aspects" and thus value is the foundation of any culture [4]. It means that cultural and linguistic competence is a set of congruent behaviors, knowledge, attitudes, relations and policies that come together in the system that enables effective work among professionals in cross-cultural situations.

Thus, in teaching humanities to medical students it is obvious to model four clusters of culture competence interpreted as:

(1) patient's cultural background (e.g., information on customs, traditions, culture, habits, values);

(2) health provider and health care (e.g., clinical skills and abilities, ethics, bioethics and deontology, awareness, patient-centeredness, and professionalism);

(3) communication skills (e.g., history, stereotype avoidance, terminology, and health disparities);

(4) cross-culture (e.g., idiomatic expressions, examples of effective communication);

(5) resources for management of cultural competency diversity (e.g., translator guides, instructions and community resources).

So, the methods for enhancing cultural competency in a multicultural Ukrainian society should be regarded as strategies presented to address the challenges of assessing teachers, parents and families of diverse culture, their beliefs, customs, traditions, and special needs. It is assumed that culture competence defines a leadership style at the educational institution and even in the group, makes key supervision of personnel actions and has a direct impact on the educational, humanitarian and learning process of medical students. Therefore, the purpose of this article is to improve the incorporation of cultural competency, cultural awareness, and cultural sensitivity in the process of teaching humanities in the medical education curricula.

\section{Discussion and Results}

Higher education is aimed at providing fundamental scientific and general culture, practical training of medical professionals. Higher medical training at the universities is specialized in improving of person's education and upbringing by enriching, amplifying and updating their professional knowledge, skills and abilities which are based on the previously received knowledge, family traditions, culture and experience. Only university education may bring up deeply moral, cultural, intellectual and highly qualified workers in the medical field. General culture includes ethical culture, general, religious and other knowledge that should be followed in one's own activities by each member of our society.

It is important to mention the influence of the family on the formation of an individual's culture competence since culture implies the received customs and traditions taken from the family but knowledge, practical experience and behavior are acquired during the study of humanitarian disciplines at higher establishments. "Culture" refers to integrated patterns of human behavior including the language, thoughts, actions, customs, beliefs, and institutions of racial, ethnic, social, or religious groups. "Competence" implies possessing the capacity to function effectively as an individual or an organization within the context of the cultural beliefs, practices, and needs presented by patients and their communities [5]. Despite the professional identity there are important characteristics of the present-day medical specialist as a sensible, balanced, restrained, moderate, intelligent and educated physician who should strictly follow ethical, bioethical and deontological norms and ethics of communication. But all these medical students' qualities may be achieved with the help of culture competence training in teaching humanities.

Moreover, teachers of humanitarian subjects have an opportunity to more thoroughly model and estimate a student's thinking processes by evaluating all the discussion and other practical assignments. The main and the most important point is the teacher's spirituality and culture, one's ability to determine the optimal intensity and quality of obtained information delivered to the students. It is known that learning environment is typically composed of 4 elements: teacher-student relationship, atmosphere of inclusion, school facilities and services, and school departments and bureaucracies [10].

According to general rules, the teacher is responsible for modelling culture competence in the process of teaching humanitarian subjects. As the researcher correctly suggests that teaching process should be focused on the "sets of rules, norms, and strategies" [11]. The teacher plays the key role in implementing the main norms and rules of culture competence into the learning process. Thus, culture competence includes cultural knowledge, sensitivity, awareness, clinical skills and abilities which constitute above-mentioned rules, norms and strategies. Every time the level of teachers' requirements obliges 
proximal development of personality and personal character in the process of teaching humanities at higher medical universities.

Supporting the idea that "Recognizing the value of positive teacher-student relationships, many education scholars have included the importance of these relationships, although usually as a side note, in their analyses of and recommendations for successful teaching and schooling” [3,9]. Therefore, the teacher has to bring language and culture into the classroom as culture is a landmark for behavior, attitude, activity and thinking at any social place or work, whether it is social or academic behavior. The better teacher understands a student's culture; the sooner one's can more fully accommodate their social and academic behavior. Nevertheless, in teaching humanities it is necessary to encourage students to express their points of view and opinions on different medical and ethical issues and share information about their culture and ethical norms creating routine medical situations.

Therefore, it is significant to analyze students' personal, social and cultural value studying humanities. Thus, it is required to support the idea that "Activities that challenge students to identify and to analyze their internalized categories enable them to see others' categories when they encounter them, and to relate that new learning to their own lived experience" [2]. Thus, students have to build meaningful and trusting relationships with other students and adults at the university; medical students should interact with each other creating culture competence, they should be motivated and be ready to learn. Hence, the institutions should compose a collaborative and cooperative environment at the universities, promoting teachers' efficiency in the capacities of culture, knowledge, values, skills and professional development, as well as enhancing the university's productivity and improving its overall performance. Nevertheless, it is useful to introduce practical strategies for empowering medical students to become active and responsible learners. Students should be motivated to take charge for their own lifelong learning and future medical carrier.

It is known that noble medical profession in accordance with special status requires not only general culture competence, but also the meaning of organizational culture, particularly in the process of higher educational training, which is aimed at advancement since the problem of cultural development stands in front of the entire Ukrainian society, and especially higher medical schools. All the same, professional culture constitutes a collection of knowledge, abilities and skills, the possession of which makes the specialist of each specific type of activity as the master of one's business [8].

Thus, the importance of interdisciplinary integration in teaching humanities to medical students becomes evident. Therefore, the degree and state of modern organizational culture of the higher medical institution depends on the level of organizational culture of teaching staff and the rector. Hence, supporting the idea that the organization is a kind of creations at the higher medical university, the leader of the educational institution like any creation, displays features of student's personal culture, one's attitudes and mistakes. The formation of normative values and basics of the student's behavior and culture provides the main features of the individual for future medical career and becomes compulsory for successful management of organizational culture, which also depends on the educational environment. It is proved that $21^{\text {st }}$ Century Educational Goals suggest a reconstruction based on different educational principles which to a degree of urgency include citizenship preparation, inclusion, and the creation of an optimum learning environment [10].

It should be emphasized that organizational culture is a complex interaction of various psychological concepts, including professional values, beliefs, norms, and ethics of members of the teaching staff, which create the motives and models for organizational work behavior, which are displayed and comprehensive to the customs and traditions of the medical university. All these concepts should be included into teaching process of humanitarian subjects to medical students.

Meanwhile, culture for doctors means not only professional communicative skills, but also clinical thinking of medical professionals and emotional exhaustion of specialists in the working place. As researcher notes "Culture contains samples of human relations: ways of perception, feeling, thinking, behavior, expressed in symbolic form" [4]. Therefore, the communicative approach focuses medical students on the need in new words, terminology, and, hence, new knowledge and even emotions. This approach activates cognitive activity, contributes to the search for modern, unusual and original forms of students' personal development that has implications for teacher-student interaction. Thus, updating the learning content of the studied humanitarian subjects, the curriculum at the medical institutions helps improve the communication skills of future medical specialists modeling cultural situations at every lesson.

Though, it should be assumed that among health professionals exists greatly developed sense of mutual support and to whose background the work and communication does not bring disappointment, especially micro-professional environment. That is why it is apparent to demonstrate the impact of different cultural, socioeconomic factors and personal characteristics of the patients' confidence in health care professionals:

- independence of opinions, combined with respect for the opinions of patients, their relatives or colleagues;

- self-esteem, assertiveness and reflection;

- the ability to navigate the world of ethics and spiritual values in the environment;

- the ability to act, make decisions and take responsibility for their actions;

- perform independent choice of the content of culture, life, thinking, behaviors, and ways of development.

All the same, it is considered that learning can provide an excellent opportunity to help medical students develop student-centered, self-directed learning skills, especially relating to cultural competence. It is necessary to build cultural environment that will support students' learning. Students as future doctors can be presented with standard cases to discuss issues relevant to current medical situations that they encounter in the clinical practice.

In supportive and responsive educational environment students feel more confident and capable of accessing the language and content, and humanitarian teachers feel more competent, and know they have done their best to meet the needs of their students. This is the basis for a logic 
conception "just in time" as a learning model that works extremely well for medical students and allows the humanitarian program to more fully integrate a permanent curricular component into the first and second year of study. It is assumed that humanitarian education at the medical university is a rather complex process due to the fact that the character of many students is predetermined by culture and family traditions which are considered to be a crucial factor in formation of young medical personality.

Therefore, formation of culture competence as a personal trait primarily implies that a person is aware of how behavior is determined by one's own inclinations and motivations, and how someone imposes settings. During the seminar medical students should discuss the activity in which they participated, what happened, what the experience meant and what they learned from it. Seminars may be used to deliver the curriculum or issue in cultural competence, but may not provide an opportunity for students to address the "whole patient" as well as problem-based or case-based sessions do, although, students may focus on specific aspects of cultural competence during the seminar or practical lesson [1]. Case-based and problem-based learning are types of seminars or practical lessons with slightly different structures, methodologies and expectations of students and teachers at the medical university. Practical lessons are intended to encourage medical students to learn at a deep level, and to apply that knowledge in a practical activity. Seminars are more generic, more loosely structured, and possibly more flexible in that students may work with a case, a selection of readings, a set of problems, or other general topics for discussion or debate. All these types of activities may be more useful for generating theoretical discussions and dialogues, such as philosophy of medicine, ethics or humanities which will be applied in future practical experience.

There are four basic cultural competence skill areas which should be implemented into teaching process of humanities:

1. Valuing diversity: Accepting and respecting different cultural backgrounds and customs, different ways of communicating, and different traditions and values.

2. Being culturally self-aware: Understanding that educators' own cultures - all of their experiences, background, knowledge, skills, beliefs, values, and interests - shape their sense of who they are, where they fit into their family, school, community, and society, and how they interact with students.

3. Understanding the dynamics of cultural interactions: Knowing that there are many factors that can affect interactions across cultures, including historical cultural experiences and relationships between cultures in a local community.

4. Institutionalizing cultural knowledge and adapting to diversity: Designing educational services based on an understanding of students' cultures and institutionalizing that knowledge so that educators, and the learning environments they work in, can adapt to and better serve diverse populations [6]. They may be applied to individual educators, to the higher institutions where they work, and to the educational system as a whole.

Nonetheless, pre-clinical students may participate in the same settings, or may be involved in service-learning projects with a variety of organizations, such as various discussions, conferences or round-table programs, etc. As medical students participate in various settings, they develop an appreciation and empathy for the predispositions, stressors, and patients' problems encountered on doctors' daily routines. Students of higher medical universities should provide a service to another person or group while developing knowledge, skills, abilities and attitudes consistent with the overall goals of the curriculum. As it was previously mentioned, medical students should demonstrate their acquisition of knowledge, ethics, behavior, attitudes, abilities and skills through reflections in seminars, projects or presentations, and even small investigations. Some studies have demonstrated that learning process in a multicultural background helps medical students to develop cultural competence at higher medical establishments and to contribute its improvement in future medical job and civic engagement.

It is suggested that cultural competence is the key component to thriving in culturally diverse groups and higher medical institutions and it can be learned, practised, and institutionalized to better understanding of diverse students, their families, and their communities. Cultural competence is the ability to successfully teach students who come from culture or cultures other than their own. It entails developing certain personal and interpersonal awareness and sensitivities, understanding certain bodies of cultural knowledge, and mastering a set of skills that, taken together, underlie effective cross-cultural teaching and culturally responsive teaching [7].

Nevertheless, the course of humanitarian disciplines may include formal or informal presentations based on the topic, discussion of the readings, raise questions, debate urgent issues or concepts, and interact with each other to develop a deeper understanding of cultural competence and basic medical concepts in future medical caregivers.

Therefore, future health professionals should learn to apply knowledge in a future clinical practice where they actually encounter real patients. That is why, it may be useful for the teacher to actively use both problem-based and project-based learning and teaching technologies in order to acquire the necessary knowledge, skills and competence in decision making under multi-changeable and variable cultural context or during difficult and risky situations. In the process of training medical professionals, tutors of humanitarian disciplines should develop medical and clinical thinking, communication, risk analysis and management, as well as students' acquaintance with different strategies in coping with stress and uncertainty that are part of medical practice. Thus, it is recommended for medical students to work with groups to identify strategies of culture competence for interacting with their class.

However, significant steps toward cultural selfunderstanding for medical students are to become fully engaged with personal perceptions, behaviors and communication patterns. Cultural competence focuses on the capacity of the health workers to improve health status by integrating culture into the clinical context. It is recommended to distinguish the following concepts of cultural competence in teaching humanities at higher medical educational establishments:

- understand the meaning of culture competence for health care providers; 
- achieve cultural competence as future doctors;

- apply cultural competence to studying process and future doctor's job;

- increase students' organizational cultural competence;

- form cross-cultural communication skills.

As it was declared formerly, prospective teachers should give medical students the chance to examine one's personal role in the process of education and formation of culture competence. The teachers of humanitarian disciplines should elaborate and implement into educational process proven strategies for empowering students to become active, responsible life-long learners and self-motivated, interdependent, self-aware, selfmanaging, self-confident, emotionally intelligent and culturally competent specialists in the field of medicine.

\section{Conclusion}

The content of modern medical education as the first level of the educational system in Ukraine is reoriented intensively into the idea of humanitarian culture, which is based on the formation of awareness, humanity and spirituality. New methods in teaching humanities are promoted by innovation, mobility and implementation of new technologies. Learning humanitarian subjects at higher medical educational establishments can provide an exceptional opportunity to help medical students develop learning skills, especially relating to culture and cultural competence. The formation of cultural competence identity in medical students is a moral requirement of humanitarian teachers. Students as future doctors can be presented with standard cases to discuss issues relevant to current medical situations and to demonstrate the impact of different cultural, socio-economic factors, personal values and characteristics of the patients' confidence in health care professionals. Thus, it is necessary to identify, prioritize and organize thoroughly components of cultural competence curriculum at higher medical educational institutions. The main and the most important point in modeling culture competence is the teacher's communication, spirituality, attitude and culture. Updating the learning content of the studied humanitarian subjects, the curriculum at the medical institutions helps improve the communication skills of future medical specialists modeling cultural situations at every lesson.

\section{Recommendation}

It is useful to introduce culture competence program into the curriculum of medical students as a separate subject that will help the humanitarian teachers to effectively teaching. If the program to "teach" cultural competence, it is generally accepted that it should be integrated throughout the entire curriculum rather than as a separate course, and so the whole university teaching staff must be involved in it and embrace it. It would be essential to elect the expert in culture competence among humanitarian teachers at higher medical establishments. The level of culture and concepts of cultural competence should be implemented into the educational process at higher medical educational institutions. It is imperative that the teachers of humanitarian disciplines should increase their intercultural competence and be involved in activities designed to enhance their ability to develop and maintain effective staff-student relationships and to increase their self-awareness.

\section{References}

[1] Barrows, H.S, Practice-Based Learning: Problem-Based Learning Applied to Medical Education, Springfield, IL: Southern Illinois University School of Medicine, 1994, 25-36.

[2] Bennet, M.J, Towards a Developmental Model of Intercultural Sensitivity. In Education for the Intercultural Experience, ed. R. Michael, Paige, Yarmouth, ME: Intercultural Press, 1993.

[3] Brown, H.D, Principals of language learning and teaching, Englewood Cliffs, NJ: Prentice Hall, 1994.

[4] Bagdasaryan, N.G, Culture: A textbook for students of technical Universities, Moscow, 2007, 511.

[5] Cross, T.L, et al. Towards a Culturally Competent System of Care: A Monograph on Effective Services for Minority Children, National Center for Cultural Competence, Georgetown University, 1989.

[6] King, M.A., Sims, A., \& Osher, D, How is cultural competence integrated into education?, Washington, D.C.: Center or Effective Collaboration and Practice, American Institutes for Research, 2007. http://cecp.air.org/cultural/Q_integrated.htm.

[7] Moule, J, Cultural Competence: A primer for educators, Belmont, CA: Wadsworth, 2012.

[8] Bogomolov, L.N, “Competence-based approach to the selection of the content of education: the case of the formation of voter competence," Standards and Monitoring in Education, 2, 19-21, 2004.

[9] Haberman, M., \& Post, L, "Teachers for multicultural schools: The power of selection,” Theory into Practice, 37 (2), 96-104.

[10] Laguardia, A., \& Pearl, A, "Necessary educational reform for the 21st century: The future of public schools in our democracy," Urban Review: Issues ad Ideas in Public Education, 41 (4), 352368, 2009.

[11] Siddiki, S., X. Barusto and C. Weible, "Comparing Formal and Informal Institutions with the Institutional Grammar Tool," Paper read at Capturing the Complexity of the Commons, North American Regional Meeting of the International Association for the Study of the Commons, 2010, Sep. 30 - Oct. 2, at Arizona State University, Tempe, AZ, USA. 